\title{
A compreensão e conceituação de livro num jogo de representações
}

\section{Comprehension and conceptualization of the book in a game of representations}

https://doi.org/10.34112/2317-0972a2016v34n67p69-82

\section{Ilsa do Carmo Vieira GoularT ${ }^{1}$}

Resumo: Com a finalidade de se compreender quais representações são construídas a respeito da obra impressa, este artigo objetiva-se a apresentar algumas concepções descritas a respeito do livro, enquanto objeto concreto de estudo e materialização das palavras. Para tanto, o trabalho destina-se a uma reflexão teórica, ao articular um espaço de exposição e dialogicidade sobre as principais proposições e discussões que abordam sobre a temática do livro impresso. Assim, destaca-se a linguagem como processo discursivo de Bakhtin, articulada à concepção de livro de Deleuze e Guattari, de Sartre e à perspectiva da História Cultural nos estudos referentes à materialidade e à história do livro de Chartier e Darnton, entre outros autores que dialogam com a temática.

Palavras-chave: Livro; materialidade; discursividade.

ABSTRACT: In order to understand which representations are made regarding the printed work, this article aims to present some described concepts about the book as a concrete object of study and materialization of words. In order to do so, the work offers a theoretical reflection, as it articulates a means of presentation and dialogism on key proposals and discussions that address the subject of the printed book. Therefore, we highlight Bakhtin's language as a discursive process, in articulation with Deleuze and Guattari's and Sartre's philosophical conception of a

1. Universidade Federal de Lavras, Lavras, MG, Brasil. 
book, and the perspective of Cultural History about studies concerning the materiality and the history of the book by Chartier and Darnton, among other authors that dialogue with the theme. KEYWORDS: Book; materiality; discursivity.

INTRODUÇÃO

Livros são papéis pintados com tinta. Estudar é uma coisa em que está indistinta A distinção entre nada e coisa nenhuma.

A ideia que se tem do livro, na atualidade, configurou-se a partir de momentos diversos de mais de cinco séculos de história da obra impressa. A invenção de Gutemberg alargou as formas de relação entre os homens e a linguagem escrita. Ao viabilizar a proximidade com o objeto-livro estimularam-se novas possibilidades de interlocução com o mundo. A circulação da palavra escrita superou os limites da oralidade, rompeu fronteiras do tempo e espaço, disseminou a capacidade inventiva e o desejo de tornar-se lembrado e eternizado pelas marcas de tintas fixadas e encadernadas em papel.

O livro, enquanto objeto físico, figurou-se através dos tempos despertando olhares e interesses pretensiosos na política, na economia, na cultura e na educação. Mais que qualquer outro objeto inventado pelo homem, nos aponta Borges (1985, p. 5), o livro diferencia-se por ser uma espécie de "extensão da memória e da imaginação", transita entre a dimensão da interioridade e da exterioridade dos sujeitos.

$\mathrm{O}$ acesso ao objeto sagrado e restrito a poucos, criou modos distintos de interação entre o leitor e o impresso, conforme nos mostram os estudos sobre a história da leitura de Chartier (1994; 1996; 1999; 2002; 2003; 2009), em que a materialidade da obra torna-se o grande investimento na conquista dos amantes e adoradores do livro.

Da posse à relação e interação, as representações sobre a obra escrita perpassaram pela ideia de supremacia, idolatria, misticismo, intelectualismo, rememoração, temor, afetividade, entretenimento, entre outras. O livro ganhou - e ainda, ganha - ao longo dos anos um espaço social de disputa e de poder, que segundo Darnton (1990), configura-se em um "circuito de comunicação". Percorre um caminho que vai do autor, editor (livreiro), o impressor, o distribuidor, o vendedor, até chegar 
ao leitor, considerando o autor também como um leitor. Um percurso é demarcado por ideias ou imagens criadas a respeito daquilo que o livro representa.

Diante disso, Chartier $(1994 ; 1999)$ chama a atenção para a distinção entre texto e impresso, entre o trabalho de produção e criação textual, o trabalho de fabricação da obra, entendendo que os autores não escrevem livros, escrevem textos que são transformados em livros, artefatos pensados e arquitetados por uma equipe editorial.

O livro, objeto concreto de materialização do texto, gerou por décadas uma preocupação não apenas cultural ou social, como também política e econômica. Tornou-se objeto comercializado e na onda capitalista ganhou status de produto altamente rentável, entre os séculos XIX e XX, como apresentam Lajolo e Zilbermam (2001), conquistando na atualidade, uma rede de disputa editorial pela liderança no mercado econômico.

Com o avanço da mídia tecnológica a partir do final do século XX, levantaram-se rumores sobre a possibilidade da queda do reinado livresco e avolumaram-se indagações e discussões sobre o futuro de obras impressas, conforme atestam Machado (1994), Chartier (1999), Zilbermam (2001), Bauman (2003), Eco e Carriére (2010). A suspeita de o livro se tornar objeto obsoleto e ultrapassado talvez tenha assombrado o império do mercado editorial, o que chama a atenção do campo acadêmico.

As preocupações sobre a temática do livro revertem-se em problematizações que privilegiam diversas temáticas investigativas, abarcando tanto a historicidade do livro e sua relação com o processo de ensino, quanto a materialidade do impresso, como as versões em e-book, abrindo múltiplas reflexões sobre a era da escrita digital.

Da adjetivação que o acompanha, como didático, de leitura, de texto, de alfabetização, paradidático, de literatura infantil ou juvenil, técnico ou científico, de entretenimento ou de informação, de imagem, e-book ou eletrônico, livro-brinquedo, entre outras denominações, o livro desperta interesses, seja com intuito da compreensão das políticas públicas ou da atividade pedagógica que o envolve, seja na apreensão de aspectos historiográficos, da materialidade, do uso de recursos tipográficos ou editoriais, percebe-se que o livro movimenta ações, preocupações e perscrutações.

Tais discussões teóricas favorecem a tecelagem de uma rede dialógica a respeito das representações e ideários que abarcam a compreensão de livro. Discursos que sinalizam uma conceituação descrita ora como objeto de concretização ou materialização da linguagem verbal e não-verbal, ora como agenciamento da exterioridade, numa articulação com outras situações, vivências, saberes, em correlação com a exterioridade, com o fora, com o por vir, como nos apontam Deleuze e Guattari (1995). 


\section{O LIVRO: DA DENOMINAÇÃO À COMPREENSÃO}

Em meio à ascendência da mídia digital, em que a linguagem escrita ganha outras configurações em softwares, e-books, CD roms, CD áudio, Ipads, aplicativos etc., em meio ao "livro eletrônico", o livro impresso ainda prevalece. Sobre sua amortização nada se sabe, apesar de nos lembrar Machado (1994, p.212) que

[...] essa é uma discussão restrita apenas aos círculos de filólogos, pois, no fundo, tudo é uma questão de definir o que estamos chamando de livro. O homem continuará, de qualquer maneira, a inventar dispositivos para dar permanência, consistência e alcance ao seu pensamento e às invenções de sua imaginação. E tudo fará também para que esses dispositivos sejam adequados ao seu tempo.

Se tudo é uma questão de definição, este trabalho parte em busca da compreensão do que ou de como, na contemporaneidade, está se denominando de livro ou obra impressa. A primeira definição parece basear-se pelas suas características físicas, como regulamentada pela UNESCO em $1964^{2}$, e incorporada no documento da ABNT NBR 6029 (2006, p. 3), que define o livro como uma "publicação não periódica que contém acima de 49 páginas, excluídas as capas, e que é objeto de Número Internacional Normalizado para Livro (ISBN)".

A definição de livro aparece com a percepção mais elaborada, quando, ao ampliar sua abrangência delimitada pela configuração externa ou física, abarca o conteúdo que o sustenta, de acordo com Faria e Pericão (2008, p. 458) descrito como:

Conjunto de cadernos, manuscritos ou impressos, costurados ordenadamente e formando um bloco - obra, científica ou literária, que forma ou pode formar um volume - cada uma das partes principais em que se dividem os textos dos livros • documento impresso ou não-impresso • transcrição do pensamento por meio de uma técnica de escrita em qualquer suporte com quaisquer processos de inscrição. O livro supõe um suporte, signos, um processo de inscrição, um significado. Integra-se num processo de criação, reprodução, distribuição, conservação e comunicação. Dirige-se a um leitor, possui uma finalidade: a reflexão, o ensino, o conhecimento, a evasão, a difusão do

2. Cf. UNESCO (1964, p.I44): "A book is a non-periodical printed publication of at least 49 pages, exclusive of the cover pages, published in the country and made available to the public." 
pensamento e a cultura • segundo a agência portuguesa para o ISBN (International Standard Book Numbering), é toda publicação não-periódica com um mínimo de quarenta e cinco páginas e que esteja sujeita a depósito legal • segundo a ISO (International Standard Organization), é publicação impressa não-periódica, com mais de quarenta e oito páginas, sem incluir as da capa, que constitui uma unidade bibliográfica; monografia • exemplar a partir do qual o editor faz a impressão.

Para além da definição que se restringe a uma classificação pelas características externas que configuram o objeto-livro, a autora destaca, ainda, os elementos semânticos que o constituem, além do processo de produção que o delimita, a quem se destina e possíveis modos de uso.

Os estudos de Ribeiro (2011, p. 4) também apresentam algumas definições de livro. Ao compará-las, a autora considera que a materialidade física se torna ponto de determinação, seja impresso ou eletrônico. Nessa rede discursiva, “[...] o livro é tomado como um objeto monolítico, muitas vezes quando se quer atribuir mais valor aos novos dispositivos usados para carregar e expor livros". Por isso, o define como “[...] uma tecnologia sócio-historicamente situada”.

A parte física do livro, é o primeiro contato desencadeador da leitura. O sujeito-leitor utiliza-se das sensações que a obra impressa pode lhe oferecer. O objeto-livro, em sua materialidade, insinua ao leitor determinadas posturas, escolhas e usos distintos, e isso se processa porque "antes de ser um texto escrito, um livro é um objeto; tem forma, cor, textura, volume, cheiro. Pode-se até ouvi-lo se folhearmos suas páginas”. (MARTINS, 1986, p. 42).

O que Mckenzie (1999) descreve como "typographic signs” e Darnton (1990) como "forma do texto" referem-se às escolhas tipográficas, como ações determinantes na produção de sentido. Trata-se da configuração de uma forma verbal única, que caracteriza aquele impresso de outra obra ou de reedições. Com certo tipo da letra, da maneira como está disposta, da organização textual que apresenta, da diagramação posta ou imposta, a obra articula um modo de expressão, que atribui certa singularidade ao trabalho de produção textual do escritor.

Nessa direção, meus estudos indicam outras definições (Cf. GOULART, 2009; 2011; 2014; e GOULART; FERREIRA, 2015), a partir da função que assume: pode se referir a ele como objeto de ensino, de reflexão, de entretenimento, como também ser uma fonte de abastecimento à memória e funcionar como um estimulador de reminiscências. Pode, também, ter a função de um objeto de representação, quando, 
ao olhar para o impresso, ao tocar, ao possuir e ao se realizar a leitura da obra, atribui-se-lhe um sentido, um valor, uma relação de afetividade.

\section{O LIVRO COMO SUPORTE DE MATERIALIZAÇÃO DA LINGUAGEM ESCRITA}

A linguagem materializada em palavras é compreendida em sua dimensão mais ampla, não apenas como um vocábulo isolado, resultante da relação grafema-fonema, mas como uma forma de expressão, como uma forma de ser e estar no mundo, que se coloca em movimento diante de mim mesma e se move em direção ao outro, em busca de outras novas palavras.

Segundo Bakhtin (2006, p. 96), a forma linguística, seja numa expressão verbal ou não-verbal, apresenta-se aos interlocutores no contexto de enunciações, o que sugere uma interação com o contexto ideológico no qual está relacionado, por isso “[...] não são palavras o que pronunciamos ou escutamos, mas verdades ou mentiras, coisas boas ou más, importantes ou triviais, agradáveis ou desagradáveis etc. $A$ palavra está sempre carregada de um conteúdo ou de um sentido ideológico ou vivencial".

Compreendendo a palavra como linguagem, como forma interlocução, Bakhtin (2006) explora a ideia de expressão em forma de enunciação como “[...] o produto da interação de dois indivíduos socialmente organizados e, mesmo que não haja um interlocutor real, este pode ser substituído pelo representante médio do grupo social ao qual pertence o locutor”.

A palavra, seja ela verbal ou não verbal, tem destino certo rumo a um interlocutor, o que o autor descreve é que a alteração da linguagem ocorre em relação a quem se dirige a palavra, visto que pode "[...] tratar de uma pessoa do mesmo grupo social ou não, se esta for inferior ou superior na hierarquia social, se estiver ligada ao locutor por laços sociais mais ou menos estreitos (pai, mãe, marido, etc.)". (BAKHTIN, 2006, p. 114).

A linguagem verbal articulada em signos gráficos e materializada em livros impressos tem na configuração do suporte a interação da palavra, demarcada por formas de interlocução previamente pensadas e articuladas pelo autor ou pelo editor, não há uma neutralidade na elaboração das obras, mas determina-se, segundo Bakhtin (2006, p. 114) “[...] tanto pelo fato de que procede de alguém, como pelo fato de que se dirige para alguém. Ela constitui justamente o produto da interação do locutor e do ouvinte”.

Dessa forma, considera-se que a produção impressa está marcada não apenas por aquele que produz a obra, como também para aquele a quem se destina a obra. 
A palavra, por ser esse lugar comum entre interlocutores, que se manifesta por discursos e, por sua vez, concretiza-se em textos, sejam eles verbais ou não verbais, permite um movimento de interação que ocorre por meio da atividade leitora, oferecendo significados múltiplos pelo leitor.

Bakhtin (2006) indica que os sentidos são construídos e atribuídos à linguagem impressa, enquanto manifestação da linguagem, enquanto movimento de interlocução verbal. O livro ganha a dimensão de linguagem materializada, corporificada.

Livro, isto é, o ato de fala impresso, constitui igualmente um elemento da comunicação verbal. Ele é objeto de discussões ativas sob a forma de diálogo e, além disso, é feito para ser apreendido de maneira ativa, para ser estudado a fundo, comentado e criticado no quadro do discurso interior, sem contar as reações impressas, institucionalizadas, que se encontram nas diferentes esferas da comunicação verbal (críticas, resenhas, que exercem influência sobre os trabalhos posteriores etc.). Além disso, $o$ ato de fala sob a forma de livro é sempre orientado em função das intervenções anteriores na mesma esfera de atividade, tanto as do próprio autor como as de outros autores: ele decorre portanto da situação particular de um problema científico ou de um estilo de produção literária. Assim, o discurso escrito é de certa maneira parte integrante de uma discussão ideológica em grande escala: ele responde a alguma coisa, refuta, confirma, antecipa as respostas e objeções potenciais, procura apoio etc. (BAKHTIN, 2006, p. 126).

O livro, para Bakhtin (2006), torna-se a concretização de um processo interdiscursivo, uma rede múltipla de interlocutores, capaz de construir diálogos outros consigo mesmo, com leitores variados, em diferentes tempos e lugares.

Essa dialogicidade decorre das relações afetivas construídas entre o leitor e o objeto-livro (GOULART, 2009; 2011; 2014). O modo como os livros se apresentam ao leitor encaminham a leitura (título, índice, notas de rodapé, referências bibliográficas, autoria). Os livros assumem determinados fins e objetivos para o leitor. São objetos provocadores de sentidos.

\section{LIVRO: DA MATERIALIDADE À UMA REDE DE ENUNCIAÇÃO COLETIVA}

O objeto-livro envolve um ato criador, pois sua existência ou reconhecimento configura-se em relação ao seu leitor. Nesse viés argumentativo, Sartre (2004, p. 47) apresenta sua compreensão de livro como algo mais abrangente, visto que "[...] cada 
livro é uma recuperação da totalidade do ser; cada um deles apresenta essa totalidade do espectador. Pois é bem esta a finalidade última da arte: recuperar este mundo, mostrando-o tal como ele é, mas como se tivesse origem na liberdade humana”.

As palavras organizadas, impressas e encadernadas compõem a obra e ali se inaugura um espaço de criação e de interlocução. A interatividade entre leitor e a obra decorre da ação leitora, uma relação que para Sartre (2004, p. 22) parece estar envolvida pela arte sedutora, inebriante e envolvente da narrativa. Considera que a palavra é transparente pois permite ver através dela, mas "[...] num livro ela se esconde, age por persuasão como o charme de uma voz ou de um rosto; não constrange, mas predispõe sem que se perceba, e acreditamos ceder a argumentos quando na verdade estamos sendo solicitados por um encanto que não se vê".

Sartre (2004) descreve, ainda, duas possibilidades de compreensão do livro: uma pela liberdade da criação que a obra inscreve ao articular tanto por parte do autor, ao escrever a obra, quanto em relação ao leitor ao exercer a ação leitora; outra pela relação de proximidade ou, quase encantamento, por uma voz que direciona o leitor, mas que, ao mesmo tempo, permite a evasão, um ir além do percebido.

É nessa oscilação entre sedução e evasão que ocorre a leitura, segundo Sartre (2004, p. 24): a atividade leitora possibilita outra forma de materialização do livro, compreendida como um ato de "possessão", pois “[...] empresta-se o corpo aos mortos para que possam reviver. [...] é um contato com o além Assim, o livro se torna capaz de provocar sentimentos e afeições, por representar "temores e esperanças defuntas", torna inteligível as emoções humanas.

Talvez nessa perspectiva de corporificação, possa se encontrar um ponto de proximidade entre a definição de Sartre e a proposta dos autores Deleuze e Guattari (1995, p. 10), que irão descrever o livro como o "corpo sem órgãos", como uma forma de "agenciamento", que regula uma multiplicidade indefinida de ações.

A ideia de agenciamento e de coletivo de enunciação atribuem ao livro não apenas uma definição limítrofe à fabricação ou marcas da exterioridade, composta de cor, forma tamanho, textura, mas desdobra-se para além de regulações que o envolvem. A ideia de agenciamento pode ser compreendida como o conjunto de forças emanadas de ações que vão desde sua composição pelo autor, a sua editoração, à disponibilização para venda, até chegar ao leitor, num "circuito de comunicação", conforme descreve Darnton (1990).

É essa ideia de agenciamento que torna o livro, segundo Deleuze e Guattari (1995, p. 10), “[...] uma espécie de organismo, ou uma totalidade significante”. Assim, 
a definição de livro assume uma complexidade que envolve tanto a materialidade física, na configuração dos dispositivos gráficos e textuais, quanto aspectos não materializados como os modos, as ações e as relações que a ultrapassam:

Um livro não tem objeto nem sujeito; é feito de matérias diferentemente formadas, de datas e velocidades muito diferentes. Desde que se atribui um livro a um sujeito, negligencia-se este trabalho das matérias e a exterioridade de suas correlações. Fabricase um bom Deus para movimentos geológicos. Num livro, como em qualquer coisa, há linhas de articulação ou segmentaridade, estratos, territorialidades, mas também linhas de fuga, movimentos de desterritorialização e desestratificação. (DELEUZE E GUATTARI, 1995, p. 10).

Para os autores o ato de escrever não se trata de um ato de significação, mas um ato de "agrimensar", de "cartografar", entre o estudar e o medir superfícies, não conhecidas, que ainda estão por vir. Isso exige tanto a capacidade de percepção, numa articulação entre o que se põe diante dos olhos e o que se oculta, quanto de tensão entre a capacidade de dedução, de inventividade, de criação imaginária.

Nesse sentido, os autores contrapõem algumas imagens de livro a partir de uma articulação com o campo das ciências biológicas. A primeira está relacionada ao "livro-raiz". Segundo Deleuze e Guattari (1995, p. 12), “[...] a árvore já é a imagem do mundo, ou a raiz é a imagem da árvore-mundo. É o livro clássico, como bela inferioridade orgânica, significante e subjetiva (os estratos do livro)".

Outra imagem trata-se do "sistema-radícula" ou da "raiz fasciculada". Se de um lado tem-se o livro-raiz, que indica a obra clássica, por outro tem-se outras obras. Para Deleuze e Guattari (1995, p. 13), o sistema-radícula surge quando “[...] a raiz principal abortou, ou se destruiu em sua extremidade: vem se enxertar nela uma multiplicidade imediata e qualquer de raízes secundárias que deflagram um grande desenvolvimento". A imagem de sistema-radícula ao livro tem sua base na grande produção de obras na modernidade, que lidam com a problemática da complexa multiplicidade do ser, do fazer, do compreender, do viver.

Nesse contexto, Deleuze e Guattari (1995, p. 13) expõem a ideia de livro como rizoma, entendendo que

O rizoma é uma antigenealogia. É uma memória curta ou uma antimemória. O rizoma procede por variação, expansão, conquista, captura, picada. Oposto ao grafismo, ao 
desenho ou à fotografia, oposto aos decalques, o rizoma se refere a um mapa que deve ser produzido, construído, sempre desmontável, conectável, reversível, modificável, com múltiplas entradas e saídas, com suas linhas de fuga. São os decalques que é preciso referir aos mapas e não o inverso.

O livro como um sistema de rizoma pode ser compreendido como algo não fechado ou limitado em si mesmo, mas como algo aberto, como um "agenciamento coletivo de enunciações" que articulam a multiplicidade em simultaneidade ao fluxo semiótico - o significado -, ao fluxo material - o significante - e ao fluxo social, diria dialógico, entre o autor e o leitor. Não se trata de uma dicotomia entre o real, a obra e a autoria, mas pensa-se em um movimento circular que envolve a tríade, em que

Não se tem mais uma tripartição entre um campo de realidade, o mundo, um campo de representação, o livro, e um campo de subjetividade, o autor. Mas um agenciamento põe em conexão certas multiplicidades tomadas em cada uma destas ordens, de tal maneira que um livro não tem sua continuação no livro seguinte, nem seu objeto no mundo nem seu sujeito em um ou em vários autores. (DELEUZE; GUATTARI, 1995, p. 13).

Segundo Malufe (2012), a importância do livro como "agenciamento coletivo de enunciações” está vinculada às coligações que o envolvem, ou seja, permite pensar ou relacionar com quais "máquinas" ele se conecta, ou com quais agenciamentos ele se configura, pensar em quais relações ele põe em jogo, que rede discursiva ele aciona ou coloca em movimento. Move-se em criação de linhas de expansão, ativando conexões e interrelações. Assim, compreende-se que "[...] um livro, um poema, uma fala, um enunciado qualquer encontra seu sentido no momento em que ele acontece para um leitor, um ouvinte, um destinatário qualquer: mesmo porvir. Ele deve ser visto como uma peça, uma pequena engrenagem de uma máquina muito maior - com a qual, ou as quais, ele irá se compor" (MALUFE, 2012, p. 201).

Tais agenciamentos não são estáticos, mas estão em constante variação, o que Deleuze e Guattari (1995), chamam de processos de "desterritorialização" e "reterritorialização". É sob a perspectiva dos agenciamentos coletivos de enunciação, inclusive, que começamos a entender um poema, um livro ou mesmo toda a obra de um escritor como território, como nos mostra Marques (2013, p. 14), tem-se na obra literária um regime de signos (uma semântica), composta por discursos indiretos que a todo instante se atravessam, num processo interdiscursivo, dialógico, 
demarcando uma interação semântica " [...] como um agenciamento maquínico de corpos que são os corpos do escritor, do livro etc.”.

Essa interação semântica é o movimento de produção de sentidos entre diferentes agenciamentos de corpos entre o autor, a produção escrita, tanto textual quanto a materialidade da obra, e o leitor.

O livro, projeto arquitetado para abarcar um texto, com certa finalidade editorial, constitui-se um agenciamento de corpos, movido por uma intencionalidade, o que escapa pela ação leitora. Num movimento de "territorialização", mas de "desterritorialização", de construção de linhas de fugas pelo leitor.

O movimento de "desterritorialização" se mostra em consonância com o que Chartier (1999, p. 19) denomina de "apropriação inventiva da obra ou do texto que recebe”. Pode-se ressaltar que a apropriação é uma produção de sentidos, ou seja, um movimento próprio de cada leitor em interlocução com o texto. Percorrem-se os terrenos da singularidade que cercam o sujeito, mas que estão em circularidade com outros "agenciamentos de corpos" ou "agenciamento coletivo de enunciações".

Compreender esse universo da materialidade requer não apenas um estudo do processo de produção deste material, mas também uma aproximação do sujeito que interage com o impresso.

\section{CONSIDERAÇões Finais}

A reflexão teórica, aqui proposta, demarca-se pelas representações do que se entende por livro, o que se depara, também, com questões descritas por Borges (1985, p. 11) "Que são as palavras impressas em um livro? Que significam estes símbolos mortos? Nada, absolutamente. Que é um livro se não o abrimos? É, simplesmente, um cubo de papel e couro, com folhas. Mas, se o lemos, acontece uma coisa rara: creio que ele muda a cada instante". Este trabalho, guiado pela finalidade de compreender algumas proposições e discussões que abordam a temática do livro impresso, apresenta algumas definições sobre o objeto-livro aproximando concepções teóricas que dialogam entre si.

As definições de livro perpassam pela compreensão da relação entre o leitor e a obra. Embora seja um suporte substancial e concreto de configuração da linguagem escrita, se considerarmos o livro apenas em seu aspecto físico e material, sem a acepção do leitor, teremos apenas um aglomerado de símbolos gráficos impressos em 
páginas sobrepostas, encadernados e envoltos por uma capa. Um objeto mórbido, repleto de palavras, mas que nada pode falar.

No entanto, se o considerarmos como um "agenciamento coletivo de enunciações”, com Deleuze e Guattari (1995), promove-se aí, por meio da materialidade do impresso, um encontro dialógico na interatividade tanto física, quanto afetiva entre o leitor e o livro.

O livro, segundo Bakhtin (2006), como um ato de fala materializado torna-se a concretização de um processo interdiscursivo e dialógico, promove uma rede de encontros e desencontros enunciativos, linhas de "desterritorialização", de fugas em busca da apropriação inventiva da obra, o que provoca ações e reações, modos distintos de ler e de compreender.

Se a relação entre leitor-texto é dinâmica e efêmera, precisar um conceito de livro torna-se uma ação complexa. Se a cada contato com este material acontecerá um novo encontro, como nos declara Chartier (1994), a leitura não será a mesma, os leitores não serão os mesmos, entende-se que os livros mudam porque os leitores mudam. Assim a compreensão do que o livro representa segue-se em perspectiva análoga. Mais que um suporte material para o texto, o livro, com o conteúdo que carrega e com a materialidade que o caracteriza, representa uma forma de expressividade e de produção de sentidos, que move ações, relações e interações em redes dialógicas.

\section{REFERÊNCIAS}

ASSOCIAÇÃO BRASILEIRA DE NORMAS TÉCNICAS. NBR 6029: informação e documentação - livros e folhetos: apresentação. 2. ed. Rio de Janeiro, 2006. Disponível em: <http://www.ufpi. $\mathrm{br} /$ subsiteFiles/ppgaarq/arquivos/files/6029-LivroseFolhetos.pdf $>$. Acesso em: 17 set. 2015.

BAUMAN, Z. O livro no diálogo global entre culturas. In: PORTELLA, E. (Org.). Reflexóes sobre os caminhos dos livros. Tradução Guilherme João de Freitas. São Paulo: UNESCO/ Moderna, 2003.

BAKHTIN, M. Marxismo e filosofia da linguagem. Tradução Michel Lahud e Yara Frateschi Vieira. São Paulo: Hucitec, 2006.

BORGES, J. L. Cinco visões pessoais. Tradução Maria Rosinda da Silva. Brasilia: UNB, 1985.

CHARTIER, R. A aventura do livro: do leitor ao navegador. Tradução Reginaldo de Moraes. São Paulo: UNESP, 1999.

- Formas e sentidos. Cultura escrita entre distinção e apropriação. Tradução Maria de Lourdes Meirelles Matêncio. Campinas: Mercado de Letras, 2003.

. História Cultural: entre práticas e representações. Tradução M. M. Galhardo. Lisboa: Difel;

Rio de Janeiro: Bertrand Brasil, 2002. 
. A história ou a leitura do tempo. Tradução Cristina Antunes. Belo Horizonte: Autêntica, 2009.

. A ordem dos livros: leitores, autores e bibliotecas na Europa entre os séculos XIV e XVIII. Tradução M. Del Priore. Brasília: Ed. UnB, 1994.

. (Org.). Práticas da leitura. Tradução Cristiane Nascimento. São Paulo: Estação da Liberdade, 1996.

DARNTON, R. O beijo de Lamourette: mídia, cultura e revolução. Tradução Denise Bottmann. São Paulo: Companhia das Letras, 1990.

DELEUZE, G.; GUATTARI, F. Mil platôs - capitalismo e esquizofrenia. Tradução Aurélio Guerra Neto e Célia Pinto Costa. Rio de Janeiro: Editora 34, 1995. vol. 1.

ECO, U.; CARRIÈRE, J. C. Não contem com o fim do livro. Tradução A. Telles. Rio de Janeiro: Record, 2010.

FARIA, M. I.; PERICÃO, M. G. Dicionário do livro. Da escrita ao livro eletrônico. São Paulo: EdUsp, 2008. GOULART, I. C. V. O livro: objeto de estudo e de memória de leitura. 2009. 200 f. Dissertação (Mestrado em Educação) Programa de Pós-Graduação em Educação, Universidade Estadual de Campinas, Campinas, 2009.

. Um livro, diferentes modos de ler. Revista Leitura: Teoria e Prática, Campinas, vol. 29, n.56, p. 27-35, jan./jun., 2011. Disponível em: http://ltp.emnuvens.com.br/ltp/issue/view/5/showToc. Acesso em: 20 jul. 2011.

. Entre a materialidade do livro e a interatividade do leitor: práticas de leitura. Revista

Digital de Biblioteconomia e Ciência da Informação, Campinas, v. 12, n. 2, p. 1-19, maio/ago. 2014. Disponível em: <http://www.sbu.unicamp.br/seer/ojs/index.php/rbci/article/view/4102/ pdf_59>. Acesso em: 28 ago. 2014.

GOULART, I. C. V.; FERREIRA, N. S. A. Relações que entremeiam leitor e livro: da materialidade à afetividade. Revista Álabe, Almería, Espanha, n. 12, p. 1-16, 2015. Disponível em: <http:// revistaalabe.com/index/alabe/issue/view/13>. Acesso em: 10 jan. 2016.

LAJOLO, M.; ZILBERMAN, R. O preço da leitura: leis e números por detrás das letras. São Paulo: Ática, 2001.

MACHADO, A. O fim do livro? Revista Estudos Avançados, São Paulo, v. 8, n. 21, p. 201-214, 1994. Disponível em: <http://www.scielo.br/pdf/ea/v8n21/13 >. Acesso em: 28 ago. 2015.

MALUFE, A. C. Aquém ou além das metáforas: a escrita poética na filosofia de Deleuze. Revista de Letras, São Paulo, v. 52, n. 2, p. 185-204, jul./dez. 2012. Disponível em: <http://seer.fclar.unesp. br/letras/issue/view/488/showToc>. Acesso em: og set. 2015.

MARQUES, M. A. Filosofia da linguagem em Bakhtin, Deleuse e Guattari: proposições teóricas para Geografia e Literatura. In: COLÓQUIO NACIONAL DO NÚCLEO DE ESTUDOS EM ESPAÇOS E REPRESENTAÇÕES, 5., 2013, Cuiabá, MT. Anais... Cuiabá: UFMT, 2013.

MARTINS, M. H. O que é leitura. 6. ed. São Paulo: Brasiliense, 1986.

MCKENZIE, D. The book as an expressive form. In: . Bibliography and the Sociology of Texts.

Cambridge University Press, 1999. p. 9-29. 
PESSOA, F. Cancioneiro. [S.1.]: Ciberfil Literatura Digital, 2002. Disponível em: <http://www3. universia.com.br/conteudo/literatura/Cancioneiro_de_fernando_pessoa.pdf $>$. Acesso em: 06 set. 2015.

RIBEIRO, A. E. O que é e o que não é um livro: suportes, gêneros e processos editoriais. In: SIMPÓSIO INTERNACIONAL DE ESTUDOS DOS GÊNEROS TEXTUAIS, 4., 2011, Natal, RN. Anais... Natal: UFRN, 2011. Disponível em: <http://www.cchla.ufrn.br/visiget/>. Acesso em: 28 ago. 2015 .

SARTRE, J.-P. O que é literatura? Tradução Carlos Felipe Moisés. São Paulo: Editora Ática, 2004.

UNESCO. Records of the General Conference. Resoluctions. Paris: Therteenth Session, 1964. Disponível em: <http://unesdoc.unesco.org/images/oo11/oo1145/114581e.pdf>. Acesso em: 17 set. 2015.

ZILBERMAN, R. Fim do livro, fim dos leitores? São Paulo: Editora SENAC, 2001.

\section{SOBRE A AUTORA}

Ilsa do Carmo Vieira Goulart é Doutora e Mestre em Educação (Universidade Estadual de Campinas), Especialista em Psicopedagogia pela Universidade Castelo Branco e Graduada em Letras (Fundação de Ensino Superior do Vale do Sapucaí). É Professora Adjunta no Departamento de Educação da Universidade Federal de Lavras. Tem experiência na área de Educação, com ênfase em EnsinoAprendizagem, atuando principalmente nos seguintes temas: história da literatura didática brasileira, cultura material escolar, leitura, livro, leitor, alfabetização e práticas de leitura. Coordena o Curso de Pedagogia da Universidade Federal de Lavras, o Núcleo de Estudos em Linguagens, Leitura e Escrita - NELLE - e o Grupo de Pesquisa Linguagem, Leitura e Cultura Escrita, da mesma universidade.

E-mail: ilsa.goulart@ded.ufla.br

Recebido em 29 de janeiro de 2016 e aprovado em 19 de agosto de 2016. 